Síntese: Revista de Filosofia adere a uma Licença Não comercial 4.0 Internacional - CReative Commons

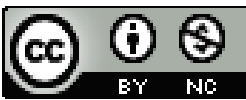

\title{
MARX, A RAZÃO E O MITO: UMA LEITURA DE HENRIQUE VAZ
}

Delmar Cardoso *

\section{O contexto do estudo de $H$. Vaz sobre Marx}

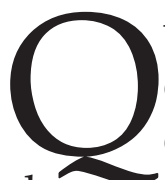
uando o assunto é filosofia no Brasil, a figura de Lima Vaz aparece com destaque e importância. Ele se mostrou um pensador que sabe conjugar a disciplina e a sobriedade da pesquisa com a criatividade de uma inteligência que percebe a profundidade dos problemas atuais. Percebe-se a importância de Henrique Vaz pelo fato da sua erudição, pela apropriação atualizada e criativa da tradição filosófica ocidental, e por ser formador de tantos intelectuais e homens públicos brasileiros. ${ }^{1}$ Ora, para sermos mais simples, convém-nos dar-lhe unicamente o epíteto de filósofo, pois em Henrique Vaz nos deparamos com uma personalidade que encarna a tarefa da Filosofia como um empenho de vida e ação.

Henrique Vaz iniciou sua docência filosófica em 1953, na Faculdade de Filosofia dos Jesuítas, então sediada em Nova Friburgo-RJ, e aí permaneceu até 1963. Desde este começo Henrique Vaz se destacou por encarar a Filosofia com a seriedade de uma tarefa profissional: aulas, pesquisas, congressos, artigos etc. Este período inicial aparece aos olhos de quem pesquisa o pensamento e a atuação de Henrique Vaz já marcado pelo labor filosófico desempenhado com determinação e competência até seus últimos dias sobre a terra. Evidentemente esses anos juvenis lhe permitiram mais desenvoltura em sua atuação. Lembre-se que nesse período ele exerceu a

* Professor da Faculdade Jesuíta de Filosofia e Teologia (FAJE), Belo Horizonte, MG. delmarcardoso@faculdadejesuita.edu.br. 
função de assistente religioso da Juventude Universitária Católica (JUC), ramo universitário da Ação Católica. ${ }^{2}$

É desses anos primeiros anos de docência que datam o seu sistemático estudo da Filosofia moderna, no qual a figura de Hegel, assume um lugar de destaque. Cabe notar que Henrique Vaz se dedica ao estudo de Hegel por um motivo progressivo e outro retroativo. O motivo progressivo deve-se ao fato de ter começado os seus estudos de Filosofia moderna com Descartes e Espinoza, culminando no pensamento de Hegel através deste que é conhecido como o "grande racionalismo". O motivo retroativo, por sua vez, se explica pela exigência de aprofundar sobre a filosofa de Karl Marx, pois o marxismo alcançou um enorme interesse, principalmente entre a juventude. Mesmo que os estudos de Henrique Vaz sobre Hegel tenham se tornado mais aprofundados e solidificados nos anos de magistério na Universidade Federal de Minas Gerais, em Belo Horizonte, onde lecionou de 1964 a 1986, ${ }^{3}$ convém marcar o início de desse aprofundamento dos estudos sobre Hegel nos primeiros anos de docência de Henrique Vaz, em Nova Friburgo.

Não podemos terminar esta breve introdução sem falar das controvérsias em torno da pessoa e do pensamento de Henrique Vaz. Há, de um lado, quem o considere "autor de uma proposta de índole totalitária mais radical que a endossada pelo Partido Comunista"; ${ }^{4}$ e, de outro, quem reconheça em sua elaboração filosófica "um dos pontos mais altos de nossa cultura filosófica e tomista". ${ }^{5}$ Como é possível que as duas afirmações se refiram à mesma pessoa? A resposta a essa pergunta se encontra na atitude de um filosofar corajoso que não teme o risco de ir às raízes da inquietação humana e que, ao mesmo tempo, mostre-se empenhado numa ação concreta e consequente ${ }^{6}$.

\footnotetext{
${ }^{1}$ SAMPAIO, Rubens Godoy. O ser e os outros: um estudo de teoria da intersubjetividade. São Paulo: Unimarco, 2001, p. 20-21.

2 OLIVEIRA, Cláudia Maria Rocha de. Metafísica e ética: a filosofia da pessoa em Lima Vaz como resposta ao niilismo contemporâneo. São Paulo: Loyola, 2013. P. 10-11.

${ }^{3}$ VAZ, Henrique Cláudio de Lima. Filosofia e forma da ação - Entrevista a Franklin Leopoldo e Silva. Cadernos de Filosofia Alemã 2, 1997, p. 78-80.

${ }^{4}$ PAIM, Antonio. História das ideias filosóficas no Brasil. 3.ed. São Paulo, Convívio, INL, Fundação Pró-Memória, 1984, p. 61.

${ }^{5}$ CAMPOS, Fernando Arruda. Tomismo no Brasil. São Paulo: Paulus, 1998, p. 142.

${ }^{6}$ Muito lúcidas a esse propósito são as palavras de Franklin Leopoldo e Silva, ao introduzir a entrevista de Henrique Vaz aos Cadernos de Filosofia Alemã: "A trajetória de Lima Vaz coincide com a consolidação dos estudos filosóficos nas Universidades brasileiras: sua contribuição só será talvez avaliada quando a importância da obra superar a discrição do autor. Coincide também com os anos de arbítrio, de repressão e de censura. A integridade do intelectual que busca na história do pensamento os meios de compreender e intervir, sem nunca ceder às seduções de imediatismo, constitui um exemplo eloquente da política como ética do compromisso: do desprendimento e da generosidade que compõem a atitude de alguém que, nas suas adesões e nas suas recusas, preserva como instância fundamentalmente inspiradora o valor do pensamento" (VAZ, 1997, p. 77).
} 


\section{Marx e a filosofia}

Entre os textos enfeixados no primeiro livro publicado, Ontologia e História, consta um denso capítulo sobre Karl Marx. Isso denota que o filósofo de Tréveris esteve entre os temas e objetos de estudo do filósofo ouro-pretano. Na advertência preliminar à primeira edição do livro Ontologia e História, o autor diz explicitamente que utilizou como critério da disposição dos capítulos a ordem cronológica das suas precedentes aparições ou como artigos ou como comunicações. ${ }^{7}$ Note-se a importância em que se pode situar seu estudo sobre Marx, pois a disposição dos capítulos de Ontologia e História reflete o caminho filosófico de Henrique Vaz: um filósofo que tem as suas bases na filosofia clássica, mas que também se encontra empenhado num profícuo e arriscado diálogo com a filosofia moderna. O estudo sobre Marx se situa nesse contexto.

Henrique Vaz não hesita em apresentar seu estudo sobre Marx entre os "Temas de Ontologia" que formam a primeira parte de Ontologia e História. Este texto sobre Marx que compõe o sexto capítulo do primeiro livro de H. Vaz se intitula Marxismo e Ontologia. ${ }^{8} \mathrm{O}$ título original do artigo era Marxismo e Filosofia, publicado numa série de três artigos em 1959. ${ }^{9}$

O início da reflexão de H. Vaz a propósito da filosofia de Karl Marx consiste na observação de que as ideias constantes no Manifesto comunista (1848) se configuraram um pouco mais de século depois em estilo de vida para um terço da população da terra. O pensamento de Marx possuiu a força de incidir concretamente na vida e no pensamento de muita gente. ${ }^{10}$

Daí que se apresenta uma primeira dificuldade: Como definir o marxismo? Vaz diz que o marxismo é visão de mundo, é sistema filosófico, é arma ideológica é técnica de análise econômica e política, é mistificação encobridora de finalidades agressivas de um imperialismo. Os marxismos são muito e é preciso fazer um esforço para ir ao encontro do "marxismo de Marx". ${ }^{11}$

Nesta busca do marxismo de Marx, Henrique Vaz atenta à primazia dada por ele ao trabalho, enquanto atividade constituidora do ser humano e da história. Nesse sentido, Vaz identifica o melhor de Marx na sua exigência da estrita racionalidade e na sua técnica rigorosa de análise, em que se

\footnotetext{
${ }^{7}$ VAZ, Henrique C. de Lima. Escritos de filosofia VI: ontologia e história. 2.ed. São Paulo: Loyola, 2001, p. 7.

${ }^{8}$ VAZ, Escritos de filosofia VI, op. cit, p. 121-161.

${ }^{9}$ Os artigos de Henrique Vaz sobre a filosofia de Marx saíram em Síntese Política Econômica e Social - primeira fase do atual periódico Síntese - Revista de Filosofia - e estavam divididos em quatro partes: as partes I e II saíram no v.1 n.1 (1959) p.29-44; a parte III saiu no v.1 n.2 (1959) p. 46-64; e a parte IV foi publicada no v.1 n.3 (1959) p.48-68.

${ }^{10}$ VAZ, Escritos de filosofia VI, op. cit. p. 121.

${ }^{11}$ Cf. Idem, p. 121-122.
} 
percebe o quanto Marx pode ser considerado um discípulo de Hegel. ${ }^{12}$ Essa filiação hegeliana confere indelevelmente identidade filosófica ao pensamento de Marx.

No entanto, Marx opera por assim dizer uma inversão na dialética de dado (limitação dos conteúdos naturais) e significado (ilimitação da consciência). Segundo a interpretação de Vaz, é preciso notar que o filósofo de Tréveris recusa a originalidade da consciência diante do mundo e deixa oscilar o esforço de transformação no dilema resolvida do processo e do fim. Assim, a consciência é abandonada à trágica ambiguidade da ação, a qual se sabe incapaz de reconhecer-se uma norma absoluta. ${ }^{13}$

Há uma exigência de totalidade que era tão reclamada na filosofia hegeliana e tão recusada por Marx. Assim, Marx, contrariamente a Hegel, não afirma a transcendência e a originalidade da consciência ou do espírito, de modo que o diálogo filosófico entre Marx e Hegel fica em situação de inacabamento, pois o materialismo dialético próprio de Marx parece igualmente rejeitar o predicado da racionalidade. ${ }^{14}$

\section{O Hegel que Marx entendeu mal}

A segunda parte do artigo de Vaz sobre Marx pode ser visto no seu todo como um elogio a Hegel. ${ }^{15}$ Já o jovem Hegel tem o mérito de perceber as contradições e dilacerações da existência humana como "manifestação de um estado 'alienado' da consciência e do ser". ${ }^{16}$

Hegel percebe a dimensão da subjetividade religiosa, qual instrumento dialético e reconciliação e integração. Marx não vê que a mediação é aprofundada na interioridade racional, nem vê "a posição do Infinito como essência espiritual e, finalmente, como condicionante não condicionado".${ }^{17}$ No Hegel da Fenomenologia do espírito, diferentemente de Schelling, é explícita a afirmação do sujeito e não a afirmação da substância, pois o sujeito se impõe categoricamente como mediação e não imediato. Daí que o sujeito "se apresenta como o Absoluto em que a mediação rompeu a identidade opaca (ponto de vista de Schelling) e abriu de si a si mesmo o espaço dialético onde se opera a definitiva reconciliação" ${ }^{18}$ Cabe à meditação do filósofo não dar realidade e vida, mas revelar a essência da realidade e da vida.

\footnotetext{
${ }^{12}$ Idem, p. 123.

${ }^{13}$ Idem, p. 126-127.

${ }^{14}$ Idem, p. 127-128.

${ }^{15}$ Idem, p. 128-135.

${ }^{16}$ Idem, p. 129.

${ }^{17}$ Idem, p. 131.

${ }^{18}$ Idem, p. 133.
} 
A dialética hegeliana confere ao sujeito que é espírito uma anterioridade às suas manifestações. Eis por que se trata de um processo dialético que significa um processo de saída do próprio espírito. Marx inverte esse processo: o dado ocupa o lugar de primazia, o manifestado assume posição de anterioridade à origem e ao ato de sua manifestação, o conteúdo natural é colocado antes da consciência.

\section{A filosofia do trabalho enquanto práxis}

As partes III e IV do estudo de Henrique Vaz sobre a filosofia de Karl Marx se constituem propriamente na sua penetração e aprofundamento nos textos do filósofo de Tréveris. ${ }^{19}$

Vaz centraliza a crítica marxiana à dialética de Hegel, principalmente na Fenomenologia do espírito, por enclausurar o processo dialético no âmbito do pensamento. ${ }^{20}$ Neste sentido, observa-se que Marx critica a atitude contemplativa como uma atitude idealista na sua essência. Vem à tona o tema do saber, compreendido como única esfera objetiva. ${ }^{21}$ Eis por que a posição de Marx é inscrita em todo o seu rigor em um materialismo dialético e isso implicará na característica marcante do seu pensamento: a militância ou o empenho na transformação do mundo. Tal atitude ganhou formulação emblemática na conhecida tese 11 das Teses sobre Feuerbach. ${ }^{22}$

Segundo Vaz, Marx pretende empreender uma transformação do mundo que "nasça de uma exigência teorética, de uma concepção de dialética que coloca o Absoluto no próprio processo de transformação". Daí que o materialismo de Marx tem no seu âmago a pretensão de uma antropogênese, vale dizer, "uma gênese do verdadeiro ser do homem libertado de suas alienações". ${ }^{23}$

Ter percebido a imbricada tensão entre ser humano e sociedade é considerada por Vaz como a mais íntima intuição de Marx. O ser do ser humano consiste no seu ser objetivo. Em outras palavras o ser do ser humano se constitui na relação dialética com a natureza. E o existir em sociedade, elemento próprio e caracterizador do ser humano, se constitui como mediação entre o ser humano e a natureza (ser-para-si e ser-para-o-outro). A consequência desta visão está no ateísmo radical de Marx que, por sua vez, também implica no seu humanismo absoluto. ${ }^{24}$

\footnotetext{
${ }^{19}$ Assim estão distribuídas estas partes: III (VAZ, Escritos de filosofia VI, op. cit. p.135-151) e IV (VAZ, Idem, p. 151-161).

${ }^{20}$ Cf. Idem, p. 138.

${ }^{21}$ Cf. Idem, p. 139.

${ }^{22}$ Cf. Idem, p. 140-141.

${ }^{23}$ Idem, p. 141.

${ }^{24}$ Cf. IDEM, p. 142-146.
} 
No humanismo marxiano a atitude contemplativa - que é própria do Idealismo - não pode ter uma significação positiva e o trabalho do pensamento permanece apenas voltada para uma perspectiva futura. Isso confere à práxis uma posição central na concepção marxiana. Eis, pois, o grande mérito e originalidade de Marx: o trabalho foi elevado por ele à condição de arché.

Henrique Vaz, na última parte do seu estudo sobre a filosofia de Marx faz a sua análise, afirmando que a filosofia de Marx termina por cair nas garras implacáveis de um mito destruidor. ${ }^{25}$

Note-se que Henrique Vaz pretende realizar um diálogo com a Filosofia moderna e elege o pensamento de Karl Marx como interlocutor importante nesse debate. Compreende-se essa escolha, se a situarmos na conjuntura histórica em que o estudo de Vaz foi realizado. Eram tempos em que parecia ter chegado à efetividade a transformação do mundo que Marx pregara como tarefa filosófica, na penúltima e mais famosa das suas teses contra Feuerbach.

Vaz lê Marx com os olhos de Hegel. A filosofia de Hegel para Henrique Vaz se mostra como uma espécie de termo no seu percurso que parte das bases sólidas do pensamento antigo para estabelecer um diálogo com a modernidade racionalista. Vaz adentra no pensamento de Hegel e no de Marx num movimento único. Ele tem a pretensão de penetrar no "misterioso Império do Meio do pensamento moderno, a obra de Hegel", e considera a filosofia marxiana como "uma província do hegelianismo em permanente estado de revolta". ${ }^{26}$

Henrique Vaz reconhece ser o marxismo uma filosofia, pois trata-se de uma visão total da realidade, cuja significação mais profunda está no valor de inteligibilidade absoluta e suprema que ele concede à práxis. Segundo Marx, duas são as dialéticas a determinar o homem como ser social: a dialética Homem-Natureza, ou seja, as forças de produção; e a dialética Homem-Sociedade, ou seja, as relações de produção. É patente que a consciência é relegada a um segundo plano em relação ao dado. Tal inversão marxiana exige a passagem da "consciência finita" ao "ser consciente", o qual se vê inserido no processo histórico. Substitui-se, pois, a consciência pelo ser consciente.

O processo histórico, por sua vez, qual corrente de inseparáveis elos, é entendido como o desenrolar necessário de estruturas que amarram o homem ao instrumento penal do próprio processo histórico, do qual só o homem mesmo poderá libertar-se. “O ato de produção, pondo em movimento a

\footnotetext{
${ }^{25}$ Idem, p. 151-161.

${ }^{26}$ VAZ, Henrique Cláudio de Lima. Bio-bibliografia. In PALÁCIO, Carlos (Org.). Cristianismo e História. São Paulo, Loyola, 1982, p. 422.
} 
tríade dialética, homem-natureza-sociedade, é o verdadeiro ato criador do processo histórico e, portanto, o "fundante' primeiro da consciência". ${ }^{27}$

Afirmando o ato de produção como o fundante absoluto do processo histórico, Marx coloca-se num plano ontológico e numa dimensão especulativa, pois há um juízo de totalidade e absoluto. Ora, somente a consciência pode ser sujeito de tal juízo. O ser consciente que é um fato, é também uma especulação. Marx então cai na contradição da abstração de um lógos do ser consciente que é mediado pelo homem histórico e real, sem perceber que "pensar a tensão dialética como Absoluto é transcendê-la. E transcender a tensão dialética é transcender a História" ${ }^{28}$

Presencia-se em Marx um dualismo insuperável entre o processo dialético como totalidade absoluta e o processo histórico como contingente. Esse dualismo contraditório acarreta à obra de Marx uma falha na sua coerência racional última e a faz ser presa fácil aos mitos de que o século XX conheceu de perto a força destruidora: a consciência revolucionária, a classe, o partido, o chefe, o comandante.

A crítica de Henrique Vaz ao pensamento de Karl Marx mostra-se contundente e dura. Ele analisa os textos de Marx e sublinha que neles há um ressurgimento de uma ontologia no interior mesmo do discurso que a nega. Diante a tal contradição, Vaz insiste mais uma vez na lição ensinada pela Ontologia clássica, para a qual "toda crítica que parte da consciência finita deverá de algum modo terminar numa Ontologia da participação a uma Consciência infinita que seja universal concreto" (VAZ, 2001, p.152). E não se pode, portanto, conceber que o mito tome o lugar pertencente ao lógos.

A crítica vaziana a Marx não se enquadra, no entanto, em simplesmente assumir a filosofia de Hegel. Esta também é estudada e criticada por ele. Mas este será assunto de outra incursão no pensamento de Henrique Vaz.

\footnotetext{
${ }^{27}$ VAZ, 2001, p. 153.
}

${ }^{28}$ Idem, p. 155. 